\section{Productive Anachronism Paper Quilling and the Craft of Architectural Representation}

Elizabeth M. Keslacy

Miami University
The materials and techniques that we use to create architectural representations undoubtedly affect how we apprehend the work of architecture being depicted. By analogy, if we consider Leonardo da Vinci's oil-on-poplar depiction of Lisa Gherardini next to a pencil sketch, a comic-book style half-tone, and a graffiti-based interpretation of the Mona Lisa, it's clear that each medium maintains its own set of associations, while, at the same time, clearly communicates its content and reference. The medium is not perhaps the whole message, but it is an important component of our experience of images and drawings.

It is also true that the choice of a particular mode of drawing during the design process can profoundly shape the object being designed. Any student of architecture can rattle off the implications of choosing Rhino, Sketch-Up, Maya, AutoCad, or Revit to work through an architectural design problem, particularly in terms of the forms and details that each software facilitates easily or with difficulty. Robin Evans' insights about drawing's fundamental difference from its content, and yet the agency it maintains in the shaping of that content, turns out to be just as true in the digital age as it was in the era of hand drawing. ${ }^{1}$

Unfortunately, the professional trend toward hyperreal image-making has meant concealing the drawing's own construction process $\neg$ es and neutering its space-generating potential. The speculative and uncertain nature of hand-production is sublimated in favor of the glossy render that makes the proposed appear as already-real. The pendulum is already swinging away from this tendency in some academic and professional circles, largely under the banner of the post-digital. ${ }^{2}$ Despite a return to orthography, collage, and an "illustrated" rather than "rendered" sensibility, the so-called post-digital largely remains stubbornly digital. How, in a world saturated with Instagram-worthy architectural images, can we teach our students to reinvest in a drawing-based design process that is experimental and open-ended? How can drawing itself be reinvigorated both in terms of its representational agency and its abilities to produce new kinds of form and space?

\section{STUDIO: PRODUCTIVE ANACHRONISM}

The upper-level undergraduate design studio that I led at Miami University in Oxford, $\mathrm{OH}$ in Spring 2010 pursued answers to these questions through a program of design research into a traditionally feminine, historical craft that has recently become new again: paper quilling. Paper quillwork, or paper filigree as it is also known, is a medium of representation dating back centuries to disputed origins, and one that took on particular importance in the United States by the 18th- and 19th-centuries. Strips of colored or gilded paper were wound in coils and pressed by hand into various geometric and organic shapes. These were then assembled into a variety of pictorial arrangements: scenes of country life featuring architectural façades, floral bouquets, and devotional objects among others. ${ }^{3}$

More recently, there has been a resurgence of interest in paper quilling at a range of levels, including fine artists, commercial graphic designers, and amateur hobbyists. This, in turn, has led to an expansion of quilling techniques that move beyond flat, coil-based practices and traditional subjects. Some contemporary quillworkers like 

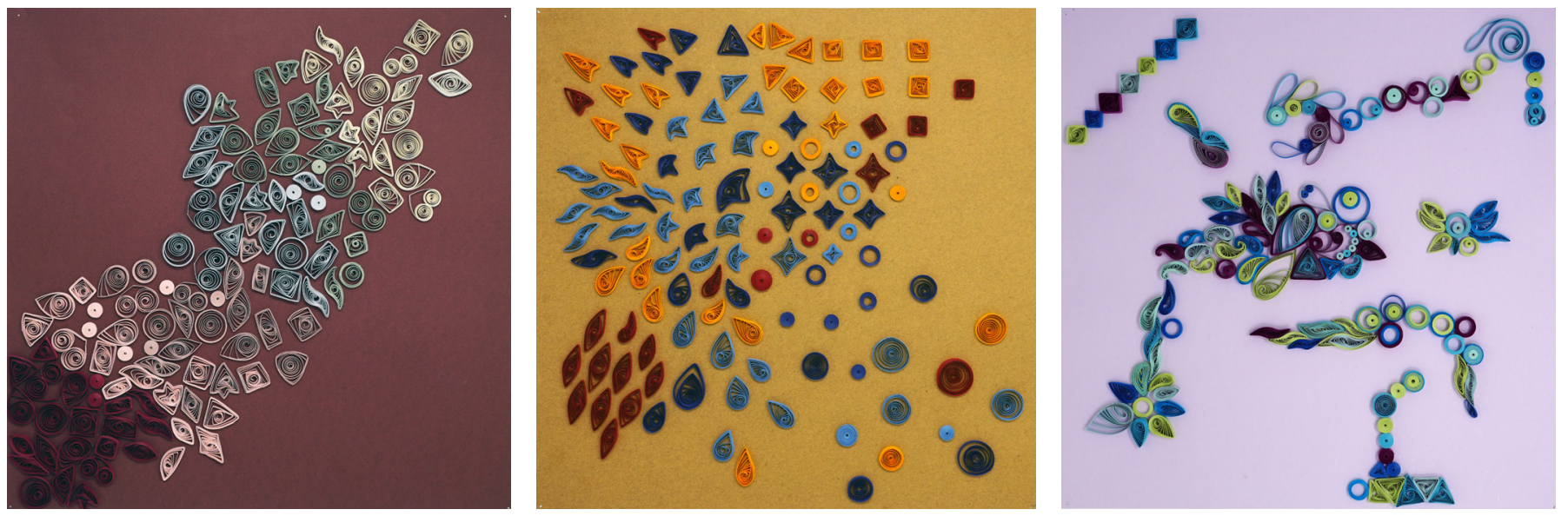

Figure 1. Quillwork Samplers by Ariana Smith (left), Rachel Staley (center), and Cooper Shira (right).

Amy Genser and Lisa Nilsson utilize three-dimensional thick shapes or finer, more precise work than we find historically. ${ }^{4}$ Other artists like Yulia Brodskaya have embraced a new graphic emphasis on outline, or they treat paper like paint to create impressionistic imagery. ${ }^{5}$ At the same time, there has been a proliferation of inexpensive tools and materials that make paper quilling one of the most accessible crafts today.

As an instructor designing a new upper-level undergraduate studio, I bet on a hunch that paper quilling could offer a great deal to architectural design and representation as an agent of innovation. The German psychologist Gerd Gigerenzer has described the "hunch" as a gut feeling or an intuition that appears quickly in consciousness and is strong enough to act upon, despite the fact that one may not fully understand its underlying reasons or logic. ${ }^{6}$ Gut feelings, or hunches, aren't just flashes of inspiration, but operate according to a heuristic rationale: simple rules of thumb that take advantage of our evolved human mental capacities. ${ }^{7}$ These are shortcuts to decision-making and ideas-generation that reduce complexities in order to posit actionable rules.

The hunch at work here was that paper quilling had something to offer to architecture. But what was the heuristic at work? If the goal was to introduce a new medium into architecture as a potential source of innovation, the heuristic was this: find something that isn't explicitly architecture which is nevertheless architectural. In other words, find something that shares some qualities with architectural drawing, but that's different enough to introduce an element of novelty. Paper quilling seemed a promising candidate.

A hunch alone is not enough to put a complex proposition into practice. Heuristics are useful in split-second decision-making, but the follow-through requires other skills. Luis Perez-Breva, director of innovation at MIT, has written about the processes by which a hunch is developed into an innovation, something he defines as both novel and impactful. ${ }^{8}$ The initial phase of this development is something he calls "innovation prototyping," a process that is incremental, nonlinear and experimental. In it, the hunch is given the structure of a smaller-scale problem that is solvable, recognizable, and verifiable. ${ }^{9}$ Only later is it scaled up.

I utilized the process that Perez-Breva describes to transform my hunch into a practicable, structured, studio-based design research inquiry. I began with a series of four short exercises designed to develop students' quilling skills, expose the biases of quilling as a representational medium, and explore how quilling techniques could be employed in an experimental, open-ended design process. I then "scaled up" for the studio's final project, which was the design of a "Museum of Minor Arts." This project presented an opportunity to instrumentalize the techniques developed in preceding experimental exercises in the service of an architectural design project. Moreover, the project's program served as a venue to think about the cultural value of the so-called minor arts, a category to which quilling belongs, through the design of spaces for their collection, exhibition, and practice.

\section{PAPER QUILLING: FROM CRAFT TO MEDIUM}

We began the series of short exercises by borrowing a format from the sister craft of embroidery - the sampler. Samplers are collections of techniques and demonstrations of skill, and they can depict a wide variety of content: alphabets and aphorisms, maps and architectural facades, abstract and floral patterns, as well as perspectival, pictorial scenes. ${ }^{10}$ For this assignment, students were asked to utilize the basic shapes of traditional quillwork to create their own sampler, composing it according to a known sampler type.

Some students hewed closely to samplers that featured repeated motifs, borders, and other linear patterns. (Figure 1) Others were inter-ested in the pictorial samplers that featured building facades or ani-mals, while yet others looked to more contemporary examples that emphasized color and composition. The students came away from this assignment with an appreciation for the necessity of good crafts-manship, and some understanding about the pictorial possibilities and limitations inherent to the quillwork shapes.

The second short assignment, entitled "Draw it New," focused more specifically on architectural representation. In it, I asked 

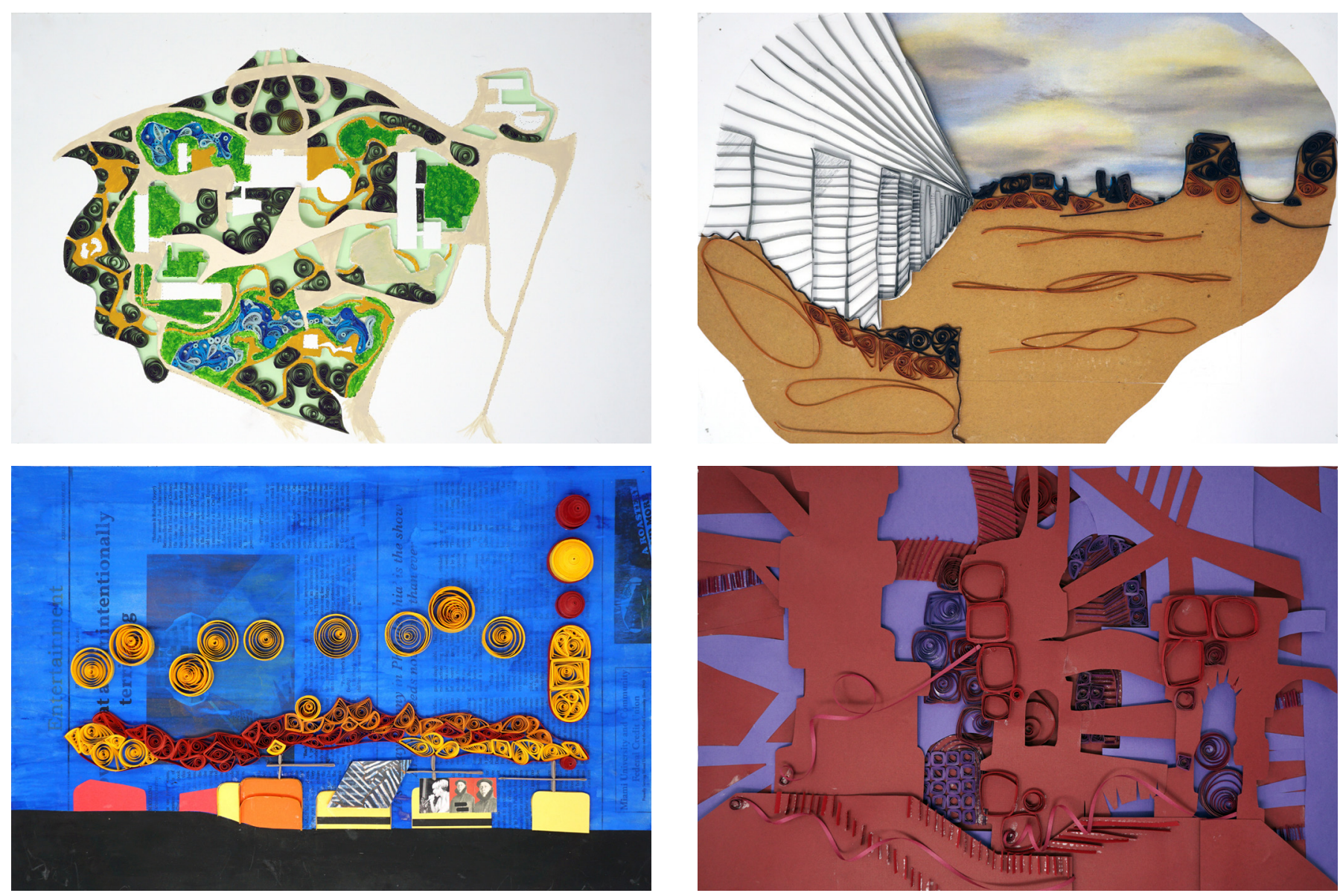

Figure 3. Examples of perspectival drawings from the Draw It New exercise. (top) Superstudio's Continuous Monument (1969-70) by Alex Bellman (bottom) Giovanni Batista Piranesi, Carceri Plate XIV (1761) by Rachel Justice.

and coil to reinterpret the drawings, and added non-quillwork element - in one case, image, and in the other, flat areas that broke down the deep space into a series of planes.

Students found other interesting strategies for dealing with the problem of depth. One student used real depth to recreate a plate from Lebbeus Woods' War and Architecture (1997), literally stacking layers of quillwork and flat paper on top of one another. (Figure 4) In an interpretation of Aldo Rossi's San Cataldo Cemetary (1971), a student used a variety of quillwork techniques, including accordion folds, rectangular coils, open swirls, and flat planes, to represent different kinds of surfaces, shadows, and elements as they layer back in space. Through this exercise, we learned that quillwork can lend an air of whimsy and informality, but it can also add texture and detail that prolongs the viewer's engagement with the drawing.

The third exercise, entitled "Type-Type," began with a purposeful elision of typography and architectural typology. In preparation for the final project, I asked students to choose an existing design museum and to extract a parti diagram from its plan that illustrated the relationship between exhibition space and all other functions. At the same time, students chose a letter from a select group of fonts. 

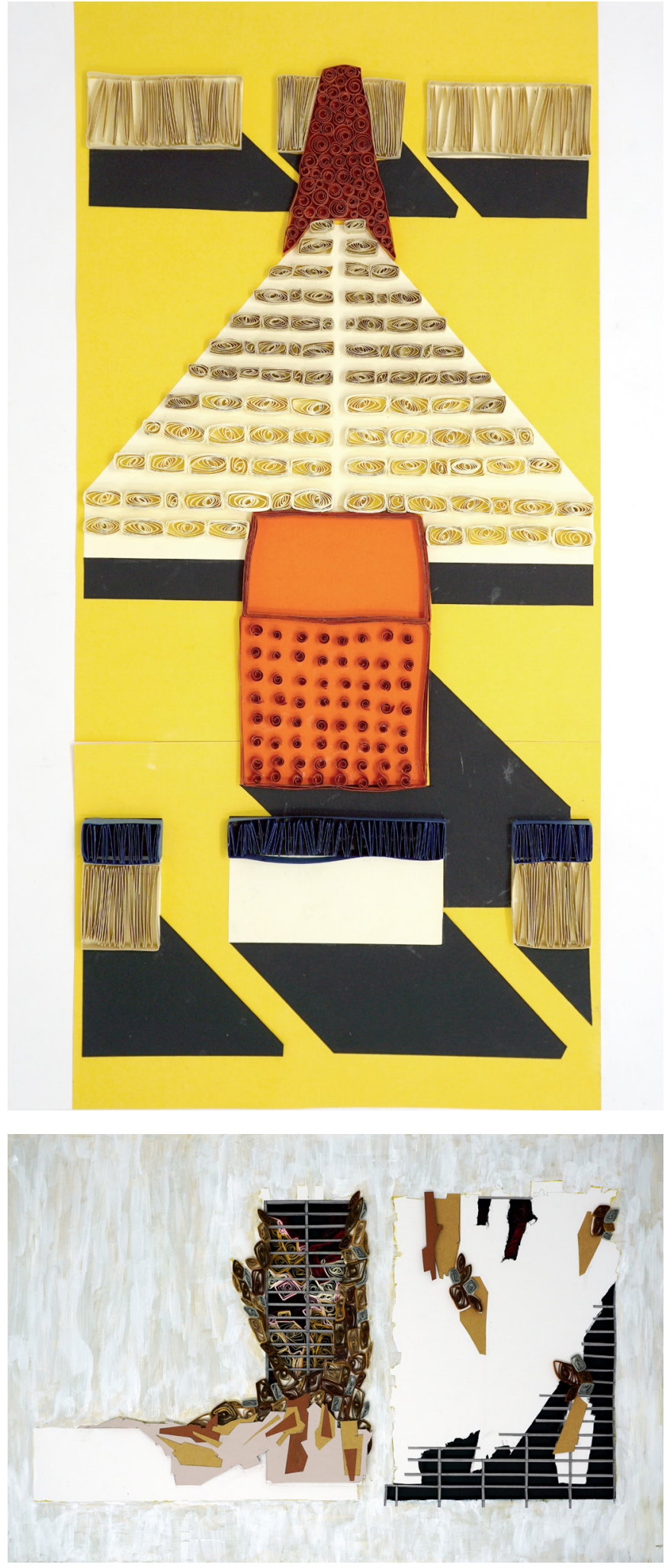

Figure 4. Examples from the Draw It New exercise.

(top) Aldo Rossi, San Cataldo Cemetary (1971) by Willow O'Keefe

(bottom) Lebbeus Woods, War and Architecture "New Parliament" (1997) by Rachel Justice.
They were asked to quill them both as base conditions. Then, they applied three kinds of transformations to both the parti diagram and the letterform - operations such as to stretch, to bend, to fragment, or to rotate.

The assignment imposed a particular attitude towards precedent-one that both learns from past projects but also subjects them to radical transformations to produce new forms and ideas. The aim here was to base those transformations in the logic of quillwork itself. Interestingly, some of the most suggestive results were those that deviated from traditional methods. Those included some that layered up or carved into the base, those that turned the strip perpendicular to its typical orientation, or manipulated the paper strip in novel ways, like crinkling.

The final exercise, entitled "Thick Form," introduced the third dimension to our quilling experiments. Up until this point, we had essentially utilized quilling in a "thick-flat" mode, meaning that the work was for the most part of uniform thickness and followed the logic of extrusion. This could also be described as "two-and-a-half dimensional." In this last assignment, the students were asked to use quillwork to turn a corner, creating a fully three-dimensional object.

Students responded in one of two ways. One set of responses created quillwork "walls" that were joined together at the corner through a simple butt-joint. (Figure 5) These walls were made more complex by changes in color or through the occasional thickening of the wall with additional quillwork elements. A second strategy involved stacking layers of quillwork shapes in one direction only to create solid thick-ness. (Figure 6) One example kept the thickness fairly uniform through-out, creating an interesting visual complexity in the view through the layers. Another utilized the same technique to create different effects on each face.

In the course of the four preliminary exercises, we used quillwork both representationally and at a one-to-one scale to immerse ourselves in its architectural possibilities. We worked planimetrically, perspectivally, abstractly and three-dimensionally - and we were ready to deploy our skills and knowledge in a more traditionally defined architectural design project.

\section{QUILLWORK AS DESIGN TOOL}

The second half the studio was thus devoted to a design project that enrolled quillwork in the design of a speculative "Cincinnati Center for the Minor Arts." The students were asked to choose a particular minor art on which their institution would focus, including architecture, the decorative arts, and folk art, among others. The program brief outlined five principle types of spaces that would make up the museum: spaces for reception and visitors, exhibition spaces, curatorial spaces, storage spaces, and maker spaces where the public could themselves engage in the chosen minor art-all for a total of 25,000 square feet.

The project was sited in Cincinnati's historic Lytle Park, home to a small, specialized fine arts institution called the Taft Museum. The Taft presents the fine and decorative arts collections of Anna Sinton Taft and Charles Phelps Taft, brother of President William Howard Taft, in a historically 

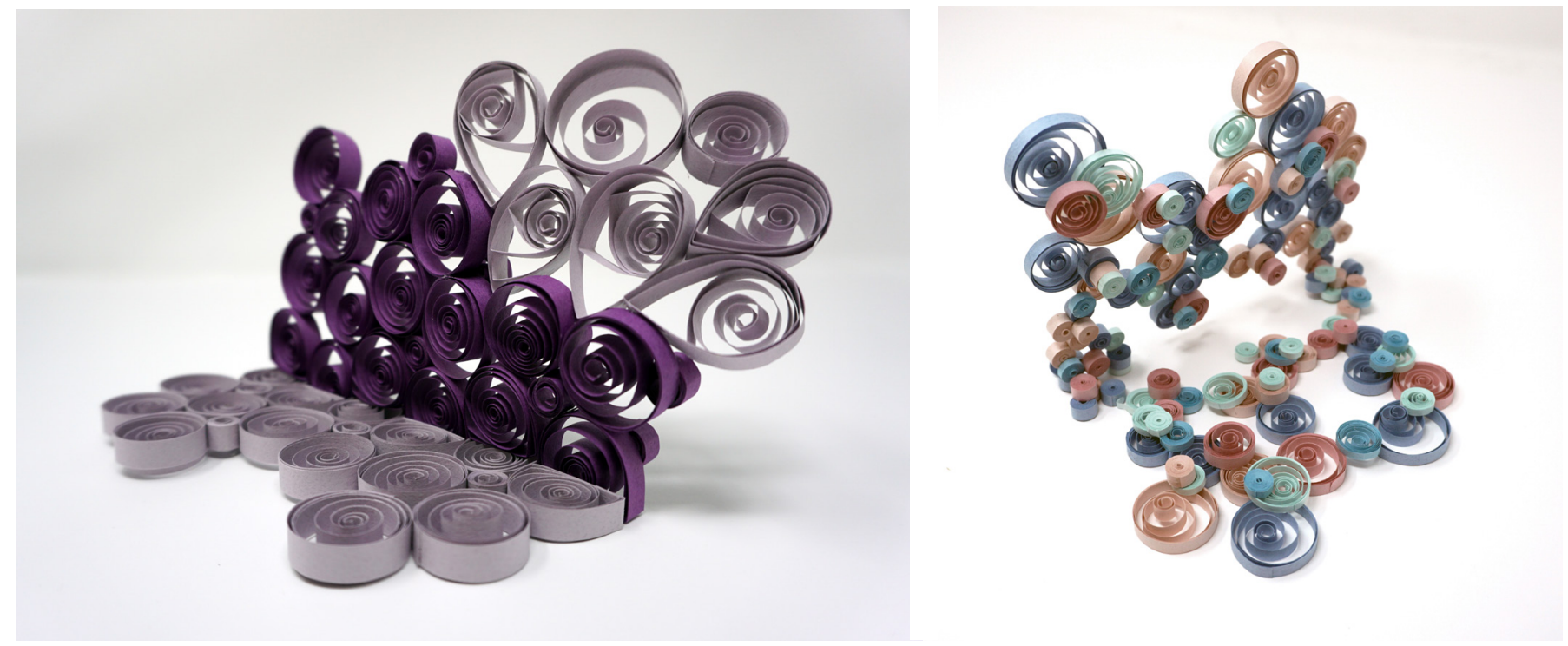

Figure 5. Examples from the Thick Form exercise depicting one common solution, the butt-joint corner. (left) Ariana Smith (right) Martha Everly
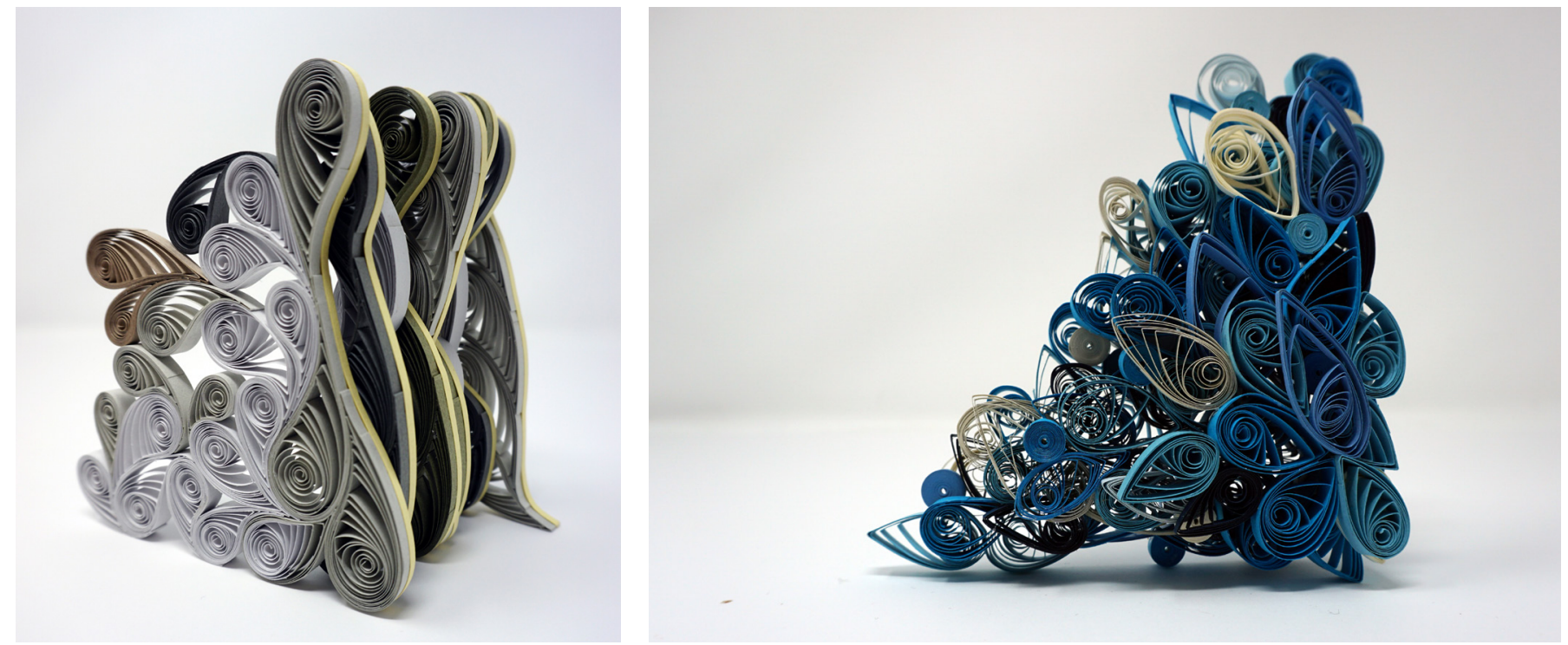

Figure 6. Examples from the Thick Form exercise depicting a second common solution using stacked layers of quillwork shapes. (left) Cooper Shira (right) Richelle Boyd

significant Federal Style structure. Our site was located just across the street from the Taft, and as such was very much in conversation with that institution.

The sequence of work on the project was not only designed to incorporate techniques of quillwork into the design process, but also to facilitate consideration of the cultural value of the minor arts. By considering how such a building is designed and organized, how it stages the display of objects and people, and how it relates to its site and surrounding neighborhood (particularly the Taft Museum), the projects could articulate something about the role of these arts in society.
The sequence of work on the project was designed to incorporate techniques of quillwork into the design process. For example, the initial work involved a series of quilled sections that articulated possible relationships between building and ground, and between the required programmatic elements. Some sections utilized the paper strips in novel ways that challenged drawing conventions. One student lifted the section cut-line off of the page to produce intriguing effects, and experimented with different tones of paper as an analog to lineweight. (Figure 7) Others utilized color and collage in combination with the paper line to articulate programmatic adjacencies. In another student's drawings, the depth of the quilled paper line became a kind 

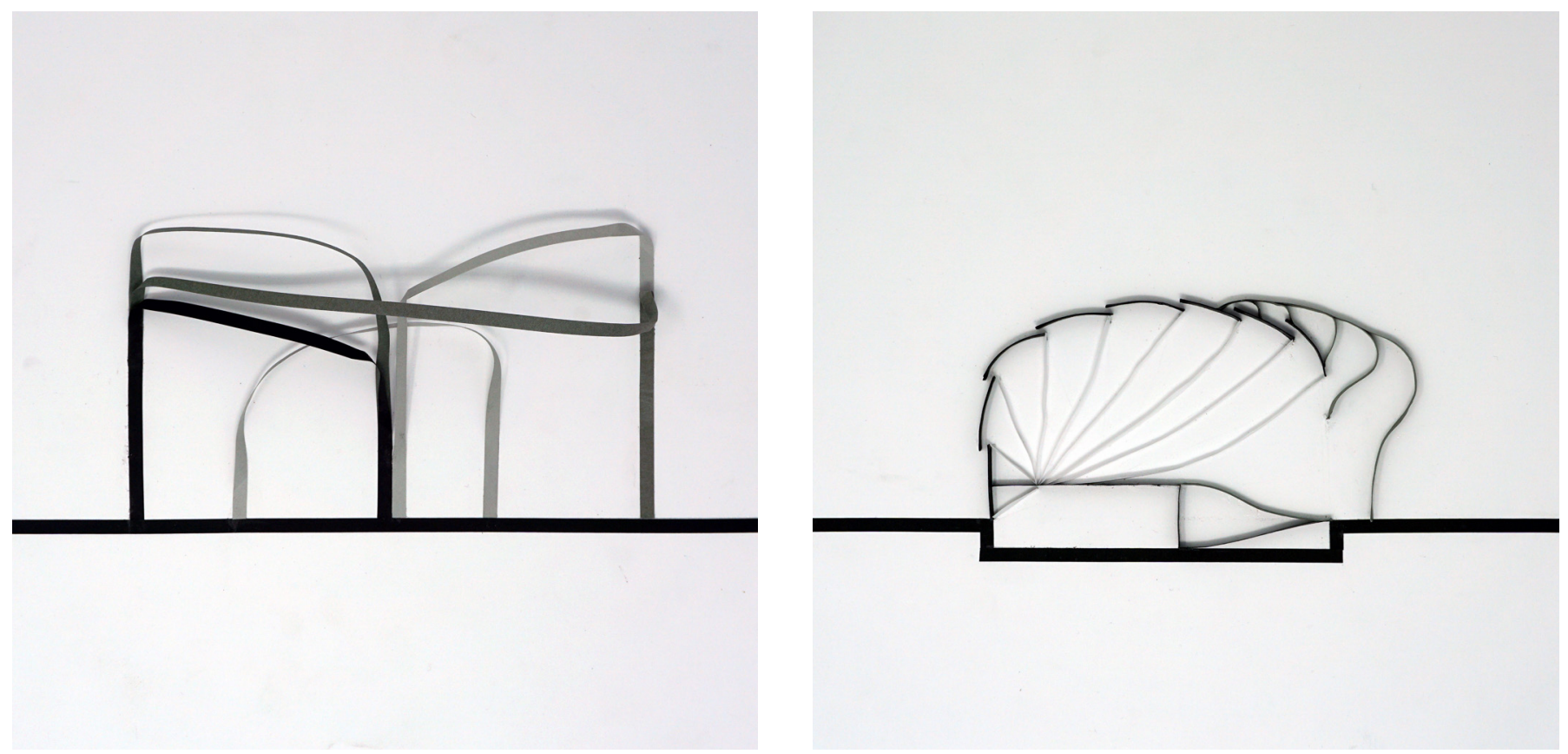

Figure 7. Speculative quillwork sections of the studio's design project, a Center for the Minor Arts, by Willow O'Keefe.

of formwork for another material-plaster-which created thickness in the drawing of a different sort. (Figure 8)

The logic of quillwork informed the projects in a variety of ways, some formally and some more conceptually. One project liberated the paper strip from the page to create a three overlapping, bulbous forms that would house her museum of paper arts. The quilled sections of this form, explored how using the paper strips both flat and on their edge in a range of tones could communicate depth.

One student decided to create a museum of ceramics, and wondered whether the site of creation-the kiln-couldn't provide formal cues for the exhibition galleries as the site of consumption. The spiral path of the rolled coil was used to organize the site and circulation. Galleries were looped around an open courtyard, with visitor spaces and offices peeling away from the core. Inside, ramps spiral up the sides of the kiln forms in a sinusoidal pattern, leading visitors to ascend and descend, to go forward and double back, adding complexity to the experience of the galleries.

Quillwork informed the display strategy of another student's project, particularly in the design of a display armature. Here the paper strip was reimagined as an endless double-sided display surface that alternated between a large platform for featured items and thickened storage to house the bulk of the collections. This armature could be woven through an open display area, be used to surround structural columns, and extend vertically to engage the second-floor catwalks that crisscrossed the space.

\section{DRAWING WITH PAPER}

Taken as a whole, the students' responses to the sequence of assignments prompts consideration of a question that is fundamental to the whole enterprise: What does it mean to draw with paper?

First, paper quilling refashions paper from a passive recipient of pencil or ink into the very medium of drawing itself. Marco Frascari has argued that paper is "an essential ingredient of architectural conceiving," ${ }^{11}$ pointing out that paper and its various qualities of texture and translucency are a necessary precondition for the process of design and documentation. In this work, paper is no longer a "passive technology," but becomes the active, mark-making device itself. Just like ink, pencil, or laser printer, the use of paper as a representational medium comes with baggage. That is, it is a medium with "tendencies" that must be acknowledged, learned, and ultimately exploited to produce its unique effects. ${ }^{12}$ For paper quillwork, those tendencies include its capacities for color, the inherency of the spiral in its coiled forms, and the shadows that are created as a corollary of its depth.

Secondly, paper quilling introduces real thickness into drawing genres, such as the plan and elevation, that have long-established conventions for representing depth. Those conventions include darker lines for objects being cut, thinner lines for objects farther away, dashed lines to indicate objects beyond or above, etc. Translating those conventions of implying depth into the a medium with real depth is not a seamless enterprise. Rather, it requires the draftsperson to grapple with those conventions, and reformulate them to account for a medium of material thickness. As such, it introduces a productive element of ambiguity into the drawing. When that happens, quillwork drawings can be interpreted in multiple ways, allowing them to be generative in modes unforeseen to the designer.

In his essay "How architectural drawings work," Sonit Bafna divided architectural drawing into two categories borrowed from the philosopher Nelson Goodman: the notational and the imaginative. 


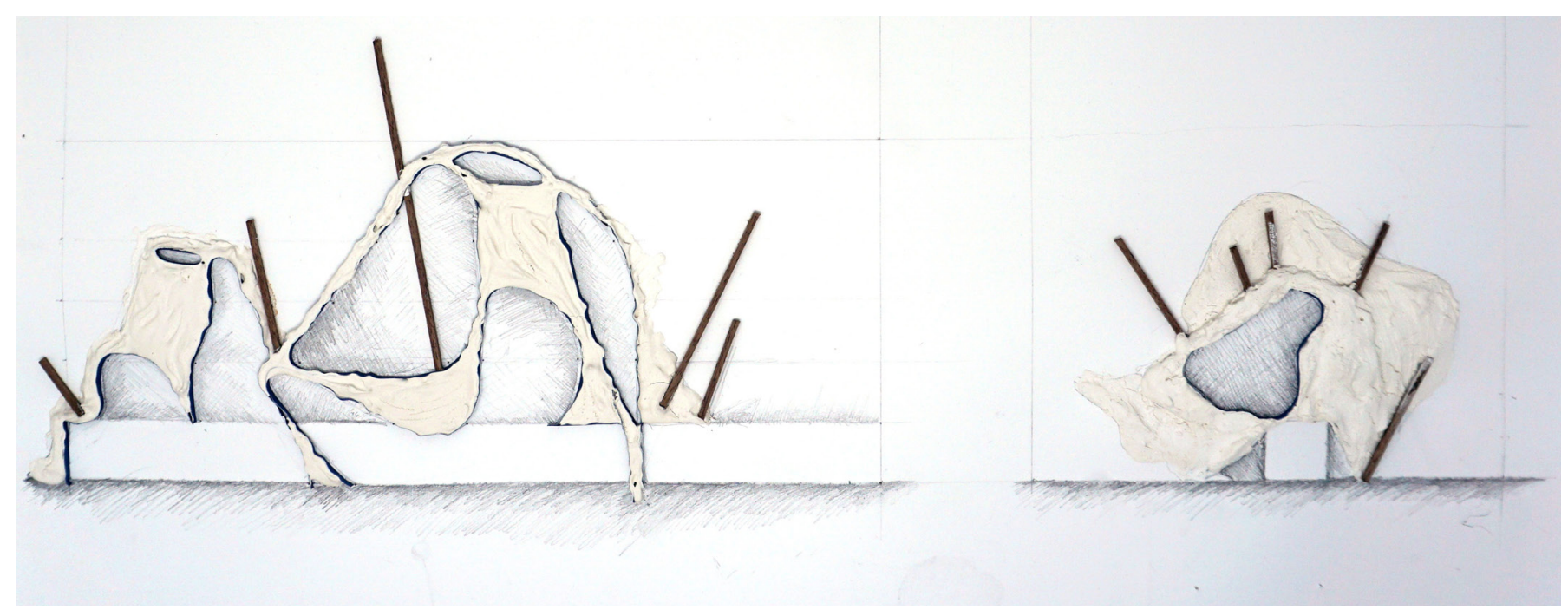

Figure 8. Speculative quillwork sections of the studio's design project, a Center for the Minor Arts, by Rachel Staley.

Notational drawings specify but do not depict, and they draw heavily on convention to create what he terms a "mechanical" relationship between drawing and object.13 Imaginative drawings, on the other hand, are primarily aesthetic in nature, and they require the viewer to engage with them creatively because of their inherent ambiguity. In notational drawings, which are most typically orthographic drawings like plan and section, the drawing medium is unremarkable and for the most part invisible to the decoding process. In contrast, drawing medium is an important element of imaginative drawings, which are often but not exclusively perspectival. Drawing on the art historian Michael Podro's work, Bafna argues that "the look of the drawing procedure" becomes "a way of perceiving what is being represented." ${ }^{14}$ In other words, how the drawing is made becomes a subject of the viewer's attention and an important factor in the viewer's understanding of its content.

The introduction of quillwork into architectural drawing ultimateIy elides the distinction between notational and imaginative drawing. Its materiality makes convention itself the site of ambiguity and play, requiring the viewer to prolong their engagement and to create rather than simply decode its meaning.

\section{Notes}

I am grateful to my colleagues at Miami University's Department of Architecture and Interior Design for their support, encouragement, and critical feedback during the studio. I am also proud of the students, who were willing to join me in this experimental process and produced work that none of us could have imagined when we began. All photographs are reproduced courtsey ofthe author.

1. Robin Evans, "Translations from Drawing to Building," in Translations from Drawing to Building and Other Essays, (Cambridge, Mass.: MIT Press, 1997), 152-93.

2. Sam Jacob, "Drawing in a Post-Digital Age," Metropolis 36, No. 8 (2017): 76-91.
3. Images of historical quillwork objects can be found in the online digital collections of the Cooper Hewitt, Smithsonian Design Museum and the Winterthur Museum, Garden, and Library.

4. See Amy Genser's work at amygenser.com. Lisa Nilsson's work can be found at lisanilssonart.com

5. See Yulia Brodskaya's work at artyulia.co.uk

6. Gerd Gigerenzer, Gut Feelings: The Intelligence of the Unconscious (New York: Viking, 2007), 16.

7. Ibid, 18.

8. Luis Perez-Breva, Innovating a Doer's Manifesto for Starting from a Hunch, Prototyping Problems, Scaling up, and Learning to Be Productively Wrong (Cambridge, MA: MIT Press, 2016), 19.

9. Ibid, 41.

10. The $V \& A$ has an excellent and well-illustrated primer on the history of embroidery samplers, at vam.ac.uk/content/ articles/h/a-history-of-samplers/

11. Marco Frascari, "A Reflection on Paper and Its Virtues within the Material and Invisible Factures of Architecture," in From Models to Drawings: Imagination and Representation in Architecture, ed. Marco Frascari, Jonathan Hale, and Bradley Starkey (London; New York: Routledge, 2007), 23.

12. Fraser and Henmi characterized the "tendencies" or biases of pencil versus ink as drawing media, describing the soft shading and taut opaque lines that they, respectively, offer. Iain Fraser and Rod Henmi, Envisioning Architecture: An Analysis of Drawing (New York: Van Nostrand Reinhold, 1994), viii.

13. Sonit Bafna, "How Architectural Drawings Work - and What That Implies for the Role of Representation in Architecture," The Journal of Architecture 13, no. 5 (2008), 537.

14. Ibid, 548 . 